\title{
Development of E-Learning Content and Delivery for Self-Learning Environment Action Case Study at Martyrs of Uganda RCJHS
}

\author{
Christiana Vormawor \\ Department of Computer \\ Science, KNUST, Ghana
}

\author{
Ussiph Najim \\ Department of Computer \\ Science, KNUST,Ghana,
}

\author{
Nuku Atta Kordzo \\ Abiew \\ Faculty of Computing and \\ Information Systems,
}

GTUC,

\author{
Baffour Owusu \\ Sekyere \\ Department of Computer \\ Science, KNUST, \\ Ghana,
}

\begin{abstract}
Advances in communication technologies have provided alternative ways to deliver instruction to students. With the advernt of the Internet as a learning tool, educators are able to use this instrument for course delivery. Information and Communications Technology (ICT) in developing countries like Ghana is considered to be essential in order to overcome the challenges that are hindering the country from developing in all sectors and also to reduce the digital break up in the Ghanaian society. As ICT is becoming more and more integrated in societies worldwide, its effects are clearly seen i.e. on peoples' lives, and on countries' economies in terms of opening doors to new opportunities and changing how people learn. In today's business and academic environment, Information Technology have become an inseparable part of many modern institutions. An effectively implemented IT solution and innovation may not only enable smooth operations, but also significantly improve the management processes. Unfortunately, despite the remarkable benefits brought by IT solutions and innovations, the Ministry of Education and the Ghana Education Service (GES) are yet to embrace and integrate this new emerging techniques into their educational curriculum in order to improve upon the teaching and learning in the country. This research aimed at examining the use of ICT tools in basic schools, particularly in the development of E-Learning content and delivery for selflearning environments.
\end{abstract}

\section{General Terms}

Electronic Learning, Instructional Designs.

\section{Keywords}

Pedagogy, Electronic, Instruction, Technology, Education

\section{INTRODUCTION}

Advances in communication technologies have provided alternative ways to deliver instruction to students. With the accessibility of the Internet as a learning tool, educators are able to use this instrument for course delivery. Information and Communications Technology (ICT) in developing countries like Ghana is considered to be a essential in order to overcome the challenges that are hindering the country from developing in all sectors and also to reduce the digital break up in the Ghanaian society. Using ICT to enhance education is one of the national strategies in Ghana. The policy and efforts are being directed at using ICT to facilitate education and learning as well as promoting e-learning and lifelong learning. Successive government has put in place measures to strengthen science education at all levels and also making effort to promote technical, vocational education and training with emphasis on the use of ICTs to facilitate the training and learning processes in schools.
This is expected to involve new technologies that help distribute education from the world's best sources to all the people who are in need of education irrespective of age, sex, creed, religion, socio-economic status; by crossing all geographical and social barriers. Through the use of new communication technologies, access to good educational programs can be greatly extended to large audiences especially in rural and remote areas with tremendous flexibility in subject matter content and in locations served. This research is exploring the use of ICT tools at the Junior High School level, specifically in the development of elearning content and delivery for self-learning environment.

This study aims at reducing the long existing problems of lack of learning and teaching resources. The research uses Martyrs of Uganda schools for the pilot study. The research applies varied principles in the development of the e-learning resources. The main participants are students and teachers of Martyrs of Uganda R/C JHS. This is an action case study type of research designed to solve a practical problem. E-learning contents will be delivered using a blended mode approach. Three delivery options are considered; using a local server for online delivery, also using Compact Disc Read Only Memory (CD-ROM) for offline delivery and lastly using the face to face (F2F) for classroom delivery.

\section{LITERATURE REVIEW}

\subsection{Introduction}

There has been no singular definition for the concept of ELearning. According to Ussiph [1] "E-learning is a new technological way to transact knowledge, or perform teaching and learning activities interactively from afar with the aid of ICT tools". E-Learning is the delivery of education and training to anyone, anytime and anywhere with help of the internet. The development and delivery of e-Learning content in current times by several organizations and institutions is under-pinned by the zeal to solve areal, learning, teaching and performance problems. The success of e-Learning depends on how learning takes place, that is, the primary pedagogy and the real assessment of e-Learning lies in the ability to arrange its attributes to train the right people to gain the right knowledge and skills at the right time. Education and training is poised to become one of the largest sectors in the world's economy. E-Learning is being recognized as having the power to transform the performance, knowledge and skills landscape [2]. Alexander[3] also opine that "E-Learning can be viewed variously as having the ability to improve the quality of learning, improve access to education and training, reduce the cost of education and improve the cost efficiency of education". According to Kanuka[4],generally, there is a universal agreement that e-Learning in some way involves the use of ICT tools in enhancing and supporting learning 
activities. Horton[5] in 2001 also believe that e-learning can be defined as the use of Internet and digital technologies to create experiences that teach other human beings. However it is important to note that an attempt to define e-Learning, from technological point of view, is to look at the relationships between e-Learning and closely relates concepts: Internetbased learning, Web-based learning, online learning, and computer-based learning as proposed by Hadjerrouit [6]. It is important to note that Internet-based learning is broader than Web-based learning, the Web is only one of the Internet services that uses the HTML, browsers and URL. Internet offers others services not only Web, but also e-mail, file transfer facilities. Siemens and Yurkiw [7] compete that students in a classroom are students and that the classroom or online refers not to the student but the means through which a student interact with the instructional content. It is therefore significant to bear in mind that e-learning is most concern about learning rather than technological aspect; that is learning with and not about technology. The function of technology is to facilitate the learning process. Holmes and Gardner [8] argue that the contribution that ICT makes to learning is not an end in itself but its impact on motivating and facilitating broader learning experience. Failure to recognize this has the possibility to upset the main purpose of e-learning settings.

\subsection{Pedagogical Overview}

Pedagogy is the means by which educational content is uncovered to learners through the use of teaching methods that relates to the presentation of experiences, engagement of learners, reinforcement, motivation, organization of teaching tasks, feedback, and evaluation. Govindaswamy [9] believes that when technology is used together with pedagogical concepts, it can create an efficient student centred environment and enhance learning outcomes. Most of the pedagogical values such as discussion, demonstration, collaborative learning, etc, that apply to the face - to - face delivery method also apply to e- Learning. However, these values need to be extended to accommodate and provide rapid changes in technology. A pedagogically designed learning content enhances the interactivity and improve retention [9]. Figure 1 illustrates the various pedagogical approaches with Trial and Error as the most overlapping processes [10]. ELearning pedagogy is based on the design of information technologies to adapt to the changing learning scenarios and various student needs. The success of learning pedagogy requires the teachers to understand how students learn and must also have the capacity and freedom to design, implement and assess educational actions that meet the needs of individual and all students [11]. Systems based on pedagogy do exist, but they give awareness to only one or a few delivery methods. And as far as the pedagogy is concerned, there is no method that is so better than others or that serves all learning needs equally well and this is applied to e- learning as well. According to Heinich et al[12], Instructional methods can be grouped as presentation, demonstration, discussion, drill-andpractice, tutorial, cooperative learning, gaming, simulation or animation, discovery, and problem solving. Technology-based approaches to learning provide many opportunities for constructivist learning; it provides and supports a resourcebased, student-centred learning environment thus enabling learning to be related to context and practice.

\subsection{Teaching and Learning Approaches}

There are varied theories and approaches to instructions. In a traditional face - to- face transmissive view, learning is based on teacher-led approach where the agency lies with the instructor; teacher constructs the learning environment and specifies what the students should do and how they should do it[13]. The learning process is comparatively passive and reactive, while the instructional object agent is relatively active and causal. Teacher-led learning approach involves methods, activities, and techniques where the teacher sends information to students and decides what to teach, how to organize the subject material, and the means of communicating the teaching material to students. Learning is judged by how well students can give feedback on what the teacher has taught them. It is argued out by some researchers that beginners should be provided with direct instructional guidance and training on the concepts and procedures required by a particular discipline and should not be left to discover those way forward by themselves [14]. At the end the agency for learning lies with the learner, learning in this instance is viewed as an active, constructive process. Learners are seen as creating new knowledge for themselves, extracting information from the environment as they see it, and meshing it with existing knowledge environment. This is known as student-led learning, it recognizes that learning solely lies with the learner. Learners decide for themselves what content to bring forward and the tutor role is more of a facilitator than instructor. The knowledge is seen as more subjective, dynamic and expanding rather than objective and static [15]. Student-led approach has different names and forms, the best known of which are discovery learning, problem based learning, inquiry learning, experiential learning and constructivist learning [16]. Constructivism stress that, participation at all levels improves responsibility and empowerment down the hierarchy, thereby flattening it. Constructivist learning is a process that is cumulative, goaloriented, self-regulated and dependent on previous relevant knowledge/skills/experience through active construction of understanding [17]. It requires enquiry-oriented pedagogies which include problem based learning, anchored instruction, cognitive apprenticeships, reciprocal teaching, goal-based and project-based learning [18]. Constructivism may have variations in active learning, discovery learning and knowledge/skills building learning. Regardless of the diversity, constructivism promotes a student's free (student centered) exploration within a given framework or structure.

\subsection{Pedagogical Consideration for E- Learning Resources}

The core learning objects are potentially a reusable component from which study course will be constructed from. In the current practice, a learning object can be a single idea or it might be a combination of several concepts to deliver a more substantial amount of learning [19]. From the learning point of view, a core learning object can composed of Information Objects (IOs), an overview, summary and assessment as illustrated in Figure 2[20]. The number of IOs depends on the time allocated for one period and the granularity of the IO.

Pedagogy encourages student's centred learning setting and produce learning material with high degree of interactivity. Sound teaching and learning materials can only be achieved if pedagogical considerations are integrated into learning materials. Pedagogical considerations should be able to help developers to engage in the process of developing e-Learning material and associated activities in a way that will enact sound principles of pedagogy. A lot of research about learning processes provide evidence for this stance that learning does not come from a provision of knowledge solely, but that it is the activities of the learners into the learning environment like 
solving problems, interacting with real devices, interacting with their social and work situation which are accountable for the learning [21]. Pedagogy for e-Leaning setting must capture most of the learning activities done in a traditional mode. In the process of content analysis, some of the pedagogical considerations for e-Learning content may include;

- Making a clear core learning objectives for each topic to be taught.

- Provision of extra references materials on a topics apart from the suggested teaching materials

- Inclusion of more assignment, drill and practices.

- Provision of regularly self-assessment exercises and right type of feedback for student's self-assessment.

- Luck of proper teaching and learning material makes the progress learning difficult.

- Much should be centered on objective oriented learning and activity based learning.

- Much should be centered on objective oriented learning and activity based learning.

The aim is to make content more attractive, interactive and self-centered learning, so that students can independently and easily follow the learning content.

\section{METHODOLOGY}

\subsection{Introduction}

Methodology in research is a form of technique or strategy adapted for conducting an inquiry that is based on some philosophical assumptions for research design and data collection [19]. Methodologies in research are broadly categorized into quantitative and qualitative, each with the philosophical assumptions, known as paradigms that show its application in research. A paradigm is a set of beliefs, and their accompanying methods, that provide a view of the nature of reality $[20,21]$. This study is a qualitative and made use of phenomenological approach in gathering data. [22] Considers this approach to the understanding and interpreting results that participants gives to their everyday lives. According to [23], qualitative approach focuses on virtues of human behavior and of which the aim of such method is not to simplify but understand and interpret the meanings and intentions that motivate everyday human actions [24]. Qualitative design deals with data that is mainly verbal and derivers meaning form participants perspective and also aim to appreciate the meaning that people attach to everyday life. This approach is appropriate for this study because the data collected will focus on the participants' subjective experiences on the process of discovery and the way they interpret them. [25] further outline that qualitative approach to research is uniquely suited to uncover the unexpected and to explore new avenues.

\subsection{Qualitative Research}

Generally, Qualitative research is based on investigations that deals with humans and social problems. Qualitative Research approach provides the basis of conducting the study in a natural setting. It also helps to build a whole and complex representation using rich report and explanation as well as careful examination of informant's words and views [17], [31], [32] and [33]. Qualitative research studies usually include ethnographies, case studies, and generally descriptive studies. Some hallmarks of qualitative research are that it is conducted in a natural environment, without attempt to deliberately manipulate the research environment. 


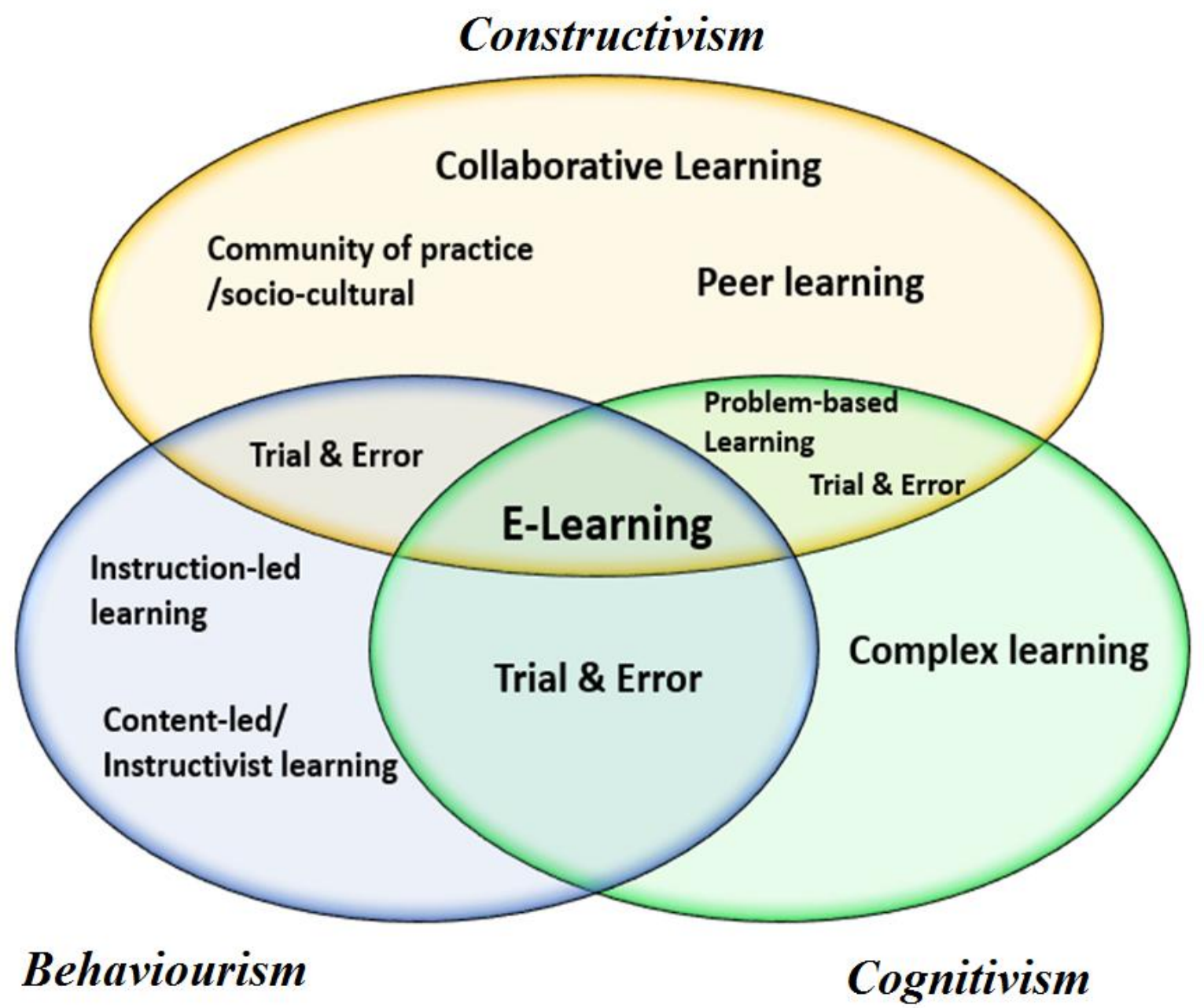

Fig 1: Overlapping theoretical underpinnings for e-learning (adapted after, Ussiph 2012)

Qualitative research belongs to the naturalist philosophical approaches that hold the belief that reality is socially constructed - that is, human beings construct their own realities and those multiple realities individuals construct, leads to the construction of an environment [26]. It also affirms the relationship between the researcher and the research as well as constraints that shapes the research process [27]. The qualitative researcher in contrast to the quantitative researcher tends to see the world as a social construction that will demonstrate large variance depending on the observer and the interpreter of the phenomenon. As such, reality is often seen as highly subjective by a qualitative researcher. Fundamental assumption underlying qualitative research is that knowledge is gained or at least filtered through social construction such as language, consciousness and shared meaning [25].

Member methods of qualitative approach to research include ethnographies, case studies, and generally descriptive studies. In contrast to quantitative methods, there is no predefinition of dependent or independent variables in qualitative method. Rather than controlling variables, qualitative studies are openended and the set up opportunities are develop to lead the researcher into unexpected areas of discovery within the research setting [28]. The authors immerses themselves in the research environment by interacting personally with subjects of the study in order to gain the subjects' perception of what is happening. They were therefore bound by values and worldviews of the subjects [26]. This thesis shed more light on qualitative research as the research topic aligns more with qualitative method rather than quantitative. Quantitative method as described in previous section is most concerned with numerical analysis and mostly aim to generate a model for predicting phenomena which is not the objective of this research. This study takes an in-depth look at the quality of social phenomena that is the way teaching and learning are delivered in Ghanaian basic schools and seeks to devise more effective ways to support teaching and learning with the aim of examining some immediate impacts. This study was conducted in a natural setting and explores all possible social variables to unearth themes and focuses within manageable boundaries. Further exploration of literature reveals three categories of qualitative research based on their underlying epistemology. These are positivist, interpretive and critical according to [17],[29] and [30] as shown in Fig 3. It has been further argue in [17], that the word 'qualitative' is not synonymous with 'interpretive' and that qualitative research may or may not be interpretive. 


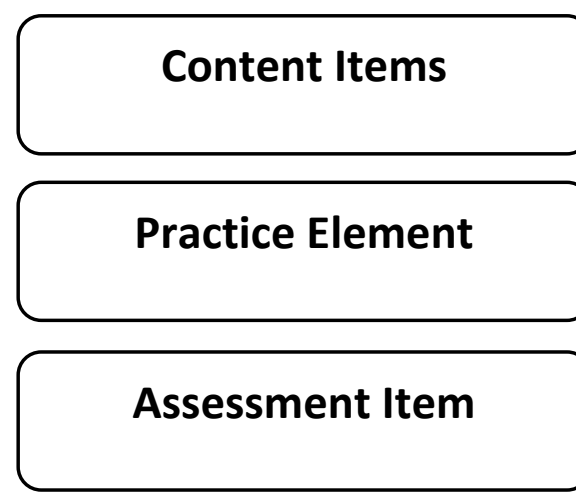

Fig 2: Composition of Information Object

\subsection{Data Gathering and Analysis Process}

The first strategy considered for this study was participatory activity research. Notwithstanding, because of constraints set on the study, action case system was thought to be most proper in this situation. The educational module and courses being offered by foundations at the Junior Secondary School level in Ghana are planned by the West Africa Examination Council. It is in this manner, out of the control of the analyst and even the school power to change the educational program of the school for all time, the researcher have no choice than to settle on action case study. Action Case method seeks to understand root cause of problems in order to predict changes of the phenomena but uses an inquiry process that is interactive and collaborative in context and balances problemsolving actions with data-driven collaborative research techniques. Common methods of primary data collection used in qualitative research include observation or participant observation, interactive interview (structured or semi structured), focus group discussion and research diary.

The implementation of actions followed from the conceptual framework by experimenting with common pedagogical strategies found in literature to design tasks and activities and then observe the learning outcomes. In the case of difficulties encountered, necessary adjustments were made by trying other pedagogical strategies or redesigning the tasks in the next cycle. These steps were repeated and outcomes observed. Participants in the research consist of 25 students in all with an average age of 12 . There were ICT Teachers that were used as facilitators. All participants including were invited to participate on voluntary basis in conformity with the research ethical requirements. Questionnaire was used to gather demographic information of participants. As the total number of participants was fairly manageable, every participant was included in the data collection

\subsubsection{Research Cycles}

The study was conducted in three phases known as cycles. The base method used in the implementation of this research project follows the widely accepted model of action case research implementation. The model implements action research in cycles, each consisting of five phases namely diagnosis, action planning, action taking, evaluating and specifying learning phases. Each cycles lasted 3 weeks and at the end of each week an evaluation, reflection and adjustment in plan for the next cycle. In each cycle, Teaching was delivered with the help of Moodle for content delivery. A 'multi-system' usage of technology and implementation of learning pedagogy was adopted. Learning pedagogy framework as shown in Fig $\mathbf{4}$ was employed to design the tasks, combined the powers of Problem-Based Learning, Inquiry Learning, collaborative and Project Based Learning (see Section 2.3) to create activities that motivate learners and challenge their acumens to improve upon their critical thinking and problem solving skills, their skills in communication and information search and processing, as well as collaboration, creativity and innovation.

\subsubsection{Evaluation and Reflection Phase}

At the end of the implementation of the three cycles, it was observed that students have improved in self-learning and are able to collaborate efficiently to solve problems. Learners' confidence in using Moodle courseware has grown significantly and they are able to pursue learning with minimal support. The course materials were found to be extremely useful as it allowed all participants to concentrate on actual learning rather than struggling to write notes while the facilitator is teaching.

A total of 16 participants and 2 support staffs were selected for interview to find out what the overall impression, impact of the project as well as learning experience of participants were. A dominant theme that emerged was the need of more technical assistance in hardware and software support, financial assistance towards provision of accessories modems and more working computers - is much needed. The need for stable power supply through provision of high quality of diesel power generator was also stressed.

In spite of technical problems encountered in the course of implementation of the research cycles, motivation was high. It was also emerged that if learners were rightly guided in selflearning and are given the opportunity and enabling environment, they can improve greatly on their performance and potential with minimal support. There was an overall consent that learning experience was far greater with this system or method of learning than in the traditional classroom method.

E-Learning is expected now more than ever, to organize and manage learning content that can be easily be searched and retrieved during the learning phase as well as to be reused for different educational purposes. With e-Learning settings, learners are allowed to easily locate and access the content of their preference. As stated earlier, the details of the implementation of the research constitute the intervention and measures taken in this study to support teaching and learning in Martyrs of Uganda R/C JHS, which is the research location. It was elaborated in detail the preparation of the participants for e-learning, the orientations organized to prepare and orient them to the use of the software applications used in the study. Tasks and activities that were carried out was in line with learning theories as espoused in the literature with particular respect to the way they have been applied in the context of this study. 


\section{FINDINGS}

This section briefly introduces and explains the computerized qualitative data analysis (CAQDAS) which was used for the analysis of the data generated in the implementation of this study. The CAQDAS was used in the themes evolved from the implementation of the intervention devised for this study which stemmed from the conceptual framework and action case research method proposed. The Data Analysis is the process of summarization and systematically applying statistical and/or logical techniques to describe and illustrate, condense and recap, and evaluate data. The core activity in much qualitative analysis is coding: the linking of one or more passages (themes) of text in one or more different documents or recordings with named analytic ideas or concepts. The software used for analysis of data for this study is Nvivo 10 . This is because Nvivo is a qualitative data analysis (QDA) computer software package produced by QSR International, which involves text-based and/or multimedia information, where deep levels of analysis on small or large volumes of data can be used.

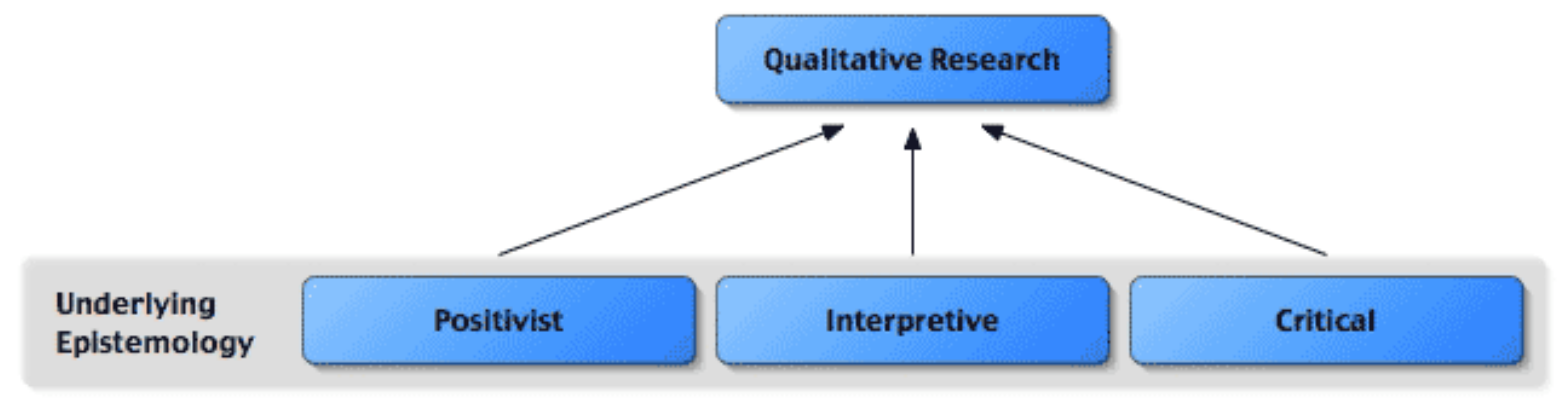

Fig 3: Underlying Epistemologies of Qualitative Research

\subsection{Organization of Data}

Participant observations and personal interviews were used to collect data during the implementation of the action research process in this study. Data collected were organized following the three stages of organizing data proposed by [34]. In the first stage, all data gathered were organized to form Sources for the Nvivo 10 'project'. Sources in Nvivo 10 are collection of documents created from recorded observations of the researcher during the research implementation and interview transcripts of interviews conducted by participants. Memos of thoughts or reflections of the researcher during research implementations can also form a source document for analysis. This stage is basically descriptive or narrative.

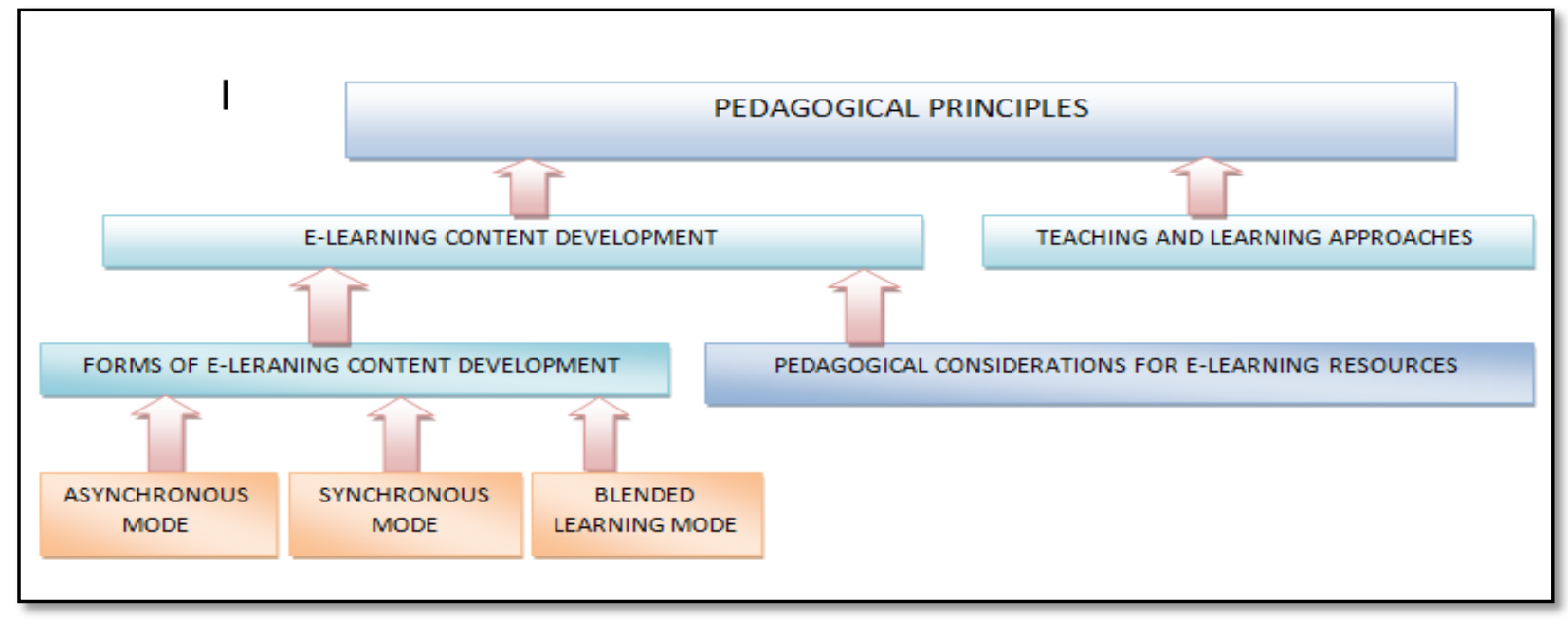

Fig 4: Conceptual Framework 


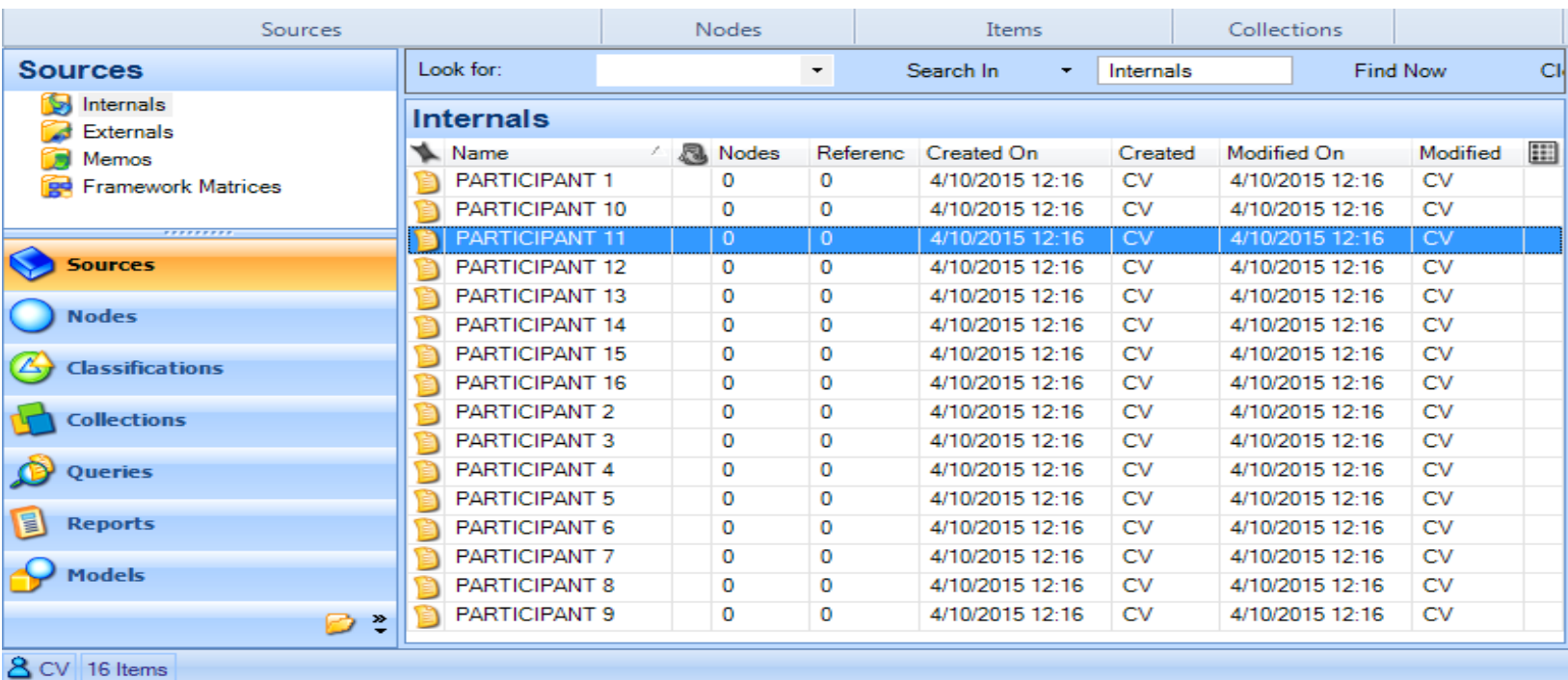

Fig 5: Participants' interviews as Sources in Nvivo 10

\subsection{Emerging Themes}

The second stage of ordering data planned by [34] involves re-arranging data according to themes or concepts. They argue that the first step in hypothesis building is conceptualizing and that a concept is a labelled phenomenon, an abstract representation of events, object, action or interaction that a research identified as being significant in the data. Concepts, themes or ideas emerging from data in the implementation of this study are packaged into nodes in Nvivo 10.

The themes that were organized into Nvivo 10 nodes evolved from the analysis of interviewees' responses to interview questions and statements made by participants in the focus group discussions during the implementation of the intervention devised for this study. The intervention took root from the conceptual framework in Figure 4 that was put forward and was based on the action case research method proposed .The pedagogies adopted in the implementation follows the underlining social constructivism nature of Moodle which is the platform for the implementation. I was guided by notions or indications of expressions that vindicated the viability, reliability and effectiveness (or otherwise) of the interventional actions that have been implemented. Rational for these criteria was informed by the objectives of this study, which was to examine the feasibility or otherwise of using elearning environment to support. At this stage, selective categorization was made to identify main categories that elucidate the final explanatory model. This categorization therefore led to the generation of the nodes.

\subsection{Analysis of Data}

Data from this study were gathered using researcher's recorded observations in memo and diary, interviews. Nvivo 10 , a qualitative software analysis tool was used in analyzing the data. Responses from participants were input into Nvivo 10 as source files as shown in Fig 6. It will be worth mentioning here that only interviews scripts of participants were coded. Observations of the researchers were mainly used to make adjustments in tasks and processes in the implementation.

Upon reviewing interview scripts and reflecting on observations from the research diary entries, issues that emerged from the data collection phases were summarized into five main themes namely impact, effectiveness, efficiency, technical problems and participants' overall view or judgment. The themes and their associates are as shown in Fig 5 and Fig 6.

The coding process was guided by the principle of hermeneutics [17] to interpret, derive meaning and understanding of text-analogue generated during interviews which were then categorized into nodes in Nvivo 10 for various themes and their associates. 


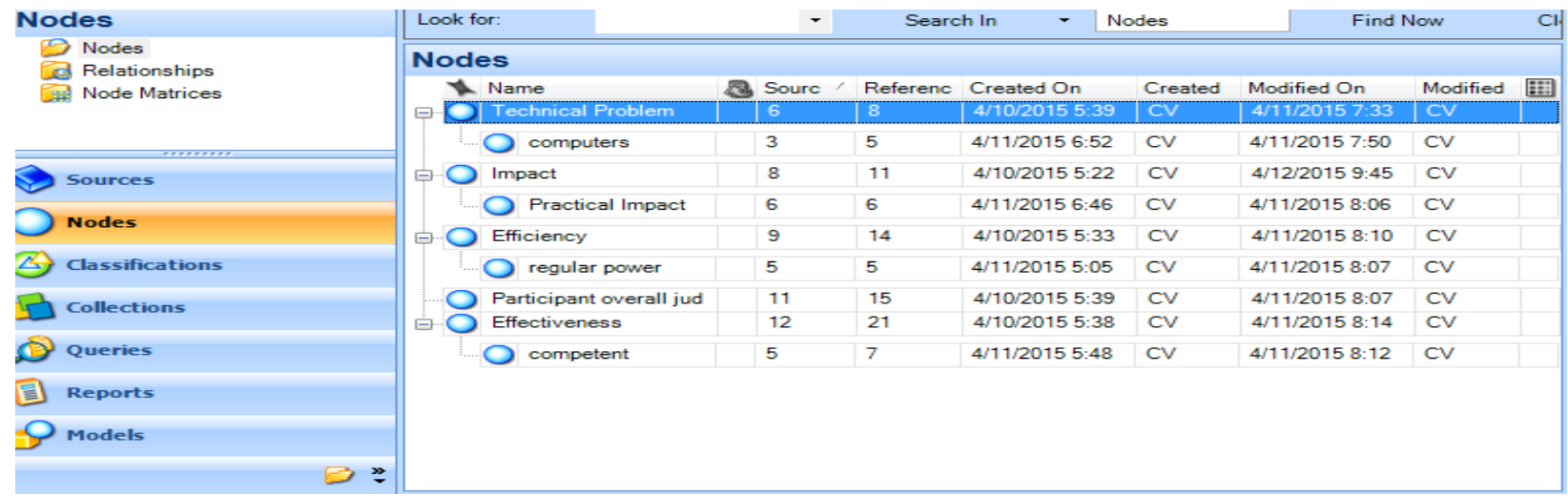

Fig 6: Themes and their associates Nodes in Nvivo 10

\begin{tabular}{|c|c|c|c|c|c|c|c|c|}
\hline Nodes & Look for: & - & Sear & ch In & Nodes & & d Now & \\
\hline $\begin{array}{l}19 \text { Nodes } \\
\text { Relationships }\end{array}$ & Nodes & & & & & & & \\
\hline Node Matrices & Name & 20urces & Refere & Created On & Created & Modified On & Modified & 暕 \\
\hline & ๓ Technical Problem & 6 & 8 & $4 / 10 / 20155: 3$ & CV & $4 / 12 / 20152: 33$ & $\mathrm{CV}$ & \\
\hline & $+\bigcirc$ Impact & 8 & 11 & $4 / 10 / 20155: 2$ & $\mathrm{CV}$ & $4 / 12 / 20152: 33$ & $\mathrm{CV}$ & \\
\hline & \# Efficiency & 9 & 14 & $4 / 10 / 20155: 3$ & $\mathrm{CV}$ & $4 / 12 / 20152: 33$ & $\mathrm{CV}$ & \\
\hline Sources & Participant overall jud & 11 & 15 & $4 / 10 / 20155: 3$ & $\mathrm{CV}$ & $4 / 12 / 20152: 33$ & $\mathrm{CV}$ & \\
\hline Nodes & OTechnical Problem $\mathbf{x}$ & & & & & & & \\
\hline $\begin{array}{l}\text { Classifications } \\
\text { Collections }\end{array}$ & $\begin{array}{l}\text { SInternalsIIPARTICIPANT } \\
\text { Reference } 1-3.12 \% \text { Cove } \\
\text { adequate computers wil }\end{array}$ & $\begin{array}{l}\text { erage } \\
114>-\S 1 \mathrm{r} \\
11 \text { the help } \mathrm{r}\end{array}$ & eference & $\begin{array}{l}\text { coded }[3.12 \\
\text { lesson very }\end{array}$ & $\begin{array}{l}\text { \% Covera } \\
\text { effectiv }\end{array}$ & ge] & & 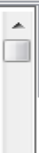 \\
\hline 国 Reports & $\leq$ Internals IIPARTICIPANT & $-15 \geq-\S 2 r$ & eference & s coded $[4.5$ & $\%$ Cover & age] & & \\
\hline$\rho_{\text {Models }}$ & $\tau_{1} \ldots . . .$. & 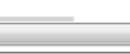 & III & 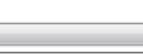 & 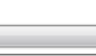 & 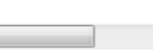 & 1. & \\
\hline
\end{tabular}

Fig 7: sample coded themes

\subsubsection{Impact}

The impact of the intervention on teaching and learning using e-learning was measured with respect to the number of participants whose responses fell under impact with the corresponding participant's model and it's associate. Figure 8 shows how the new system have had a great impact on their learning outcomes of the participants. It was the aim of study to determine how the intervention has impacted on students through teaching and learning, however, the direction or various ways the intervention had impacted on student was not pre-determined. It was left open for participants to express these in terms of their experiences using the system or the new technique. From the above codes, majority of participants responded positively to the fact that the new technology has greatly motivated and increased their academic performance greatly.

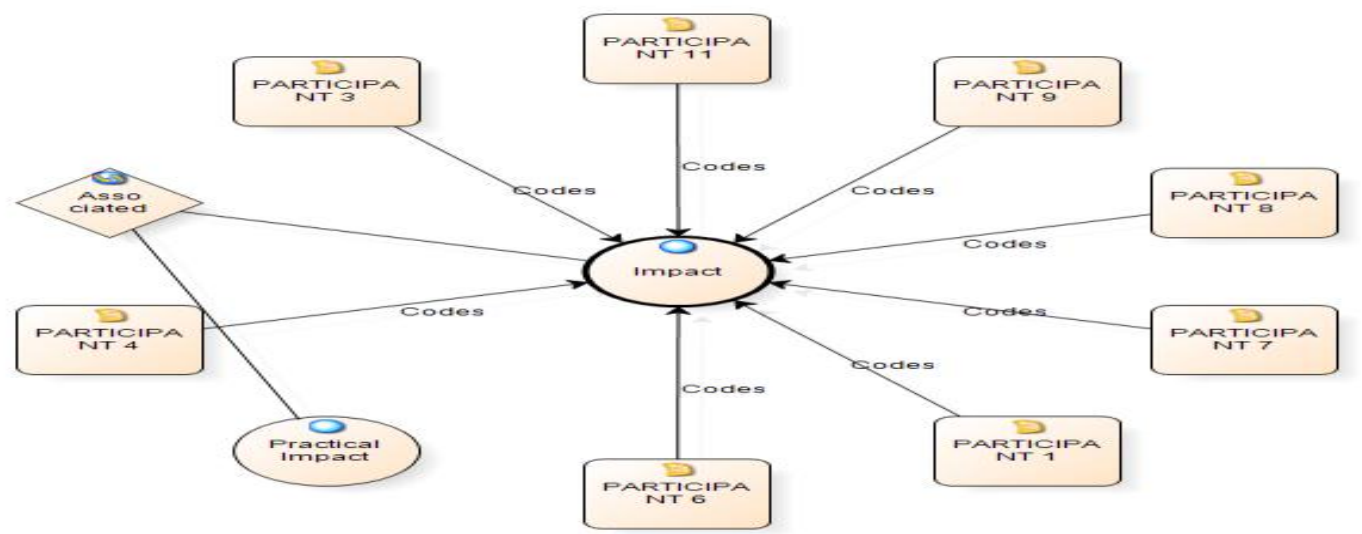

Fig 8: participant's source coded under impact and its associates 


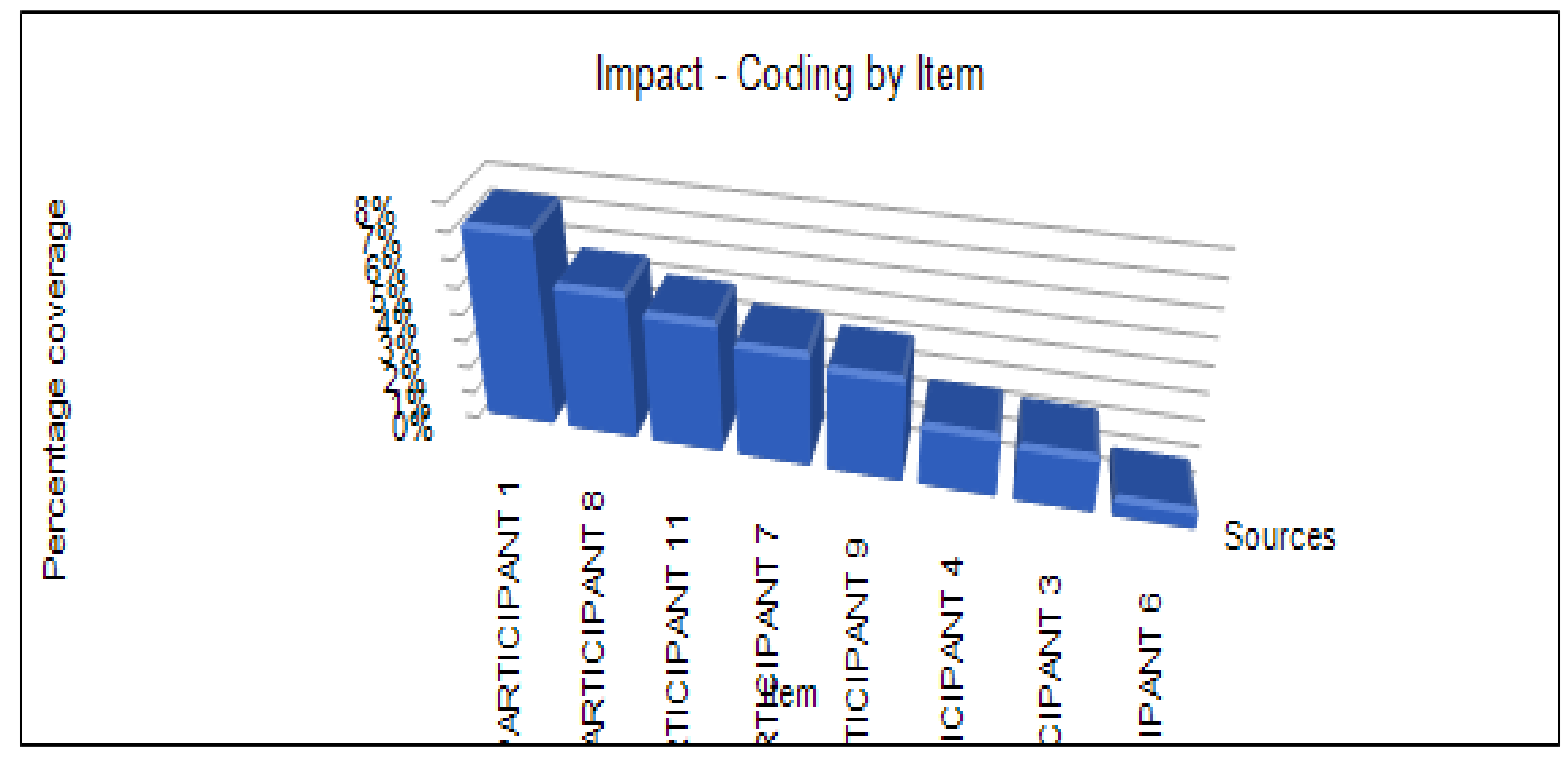

Fig 9: Chart showing Impact themes coding

\subsubsection{Effectiveness}

Effectiveness of the intervention, which is the new learning system, was measured with many participants who responded positively to the use of e- learning system to support teaching and learning. By effectiveness, we mean how successful, especially in the way of improving teaching in the school. Whether it has been effective or not? Has the new technique been easy to use or not? Responses to these experiences of participants are coded under the node, Effectiveness with its corresponding chart to support how effective the new system is. This evidence is illustrated in Figure 10 and Figure 11.

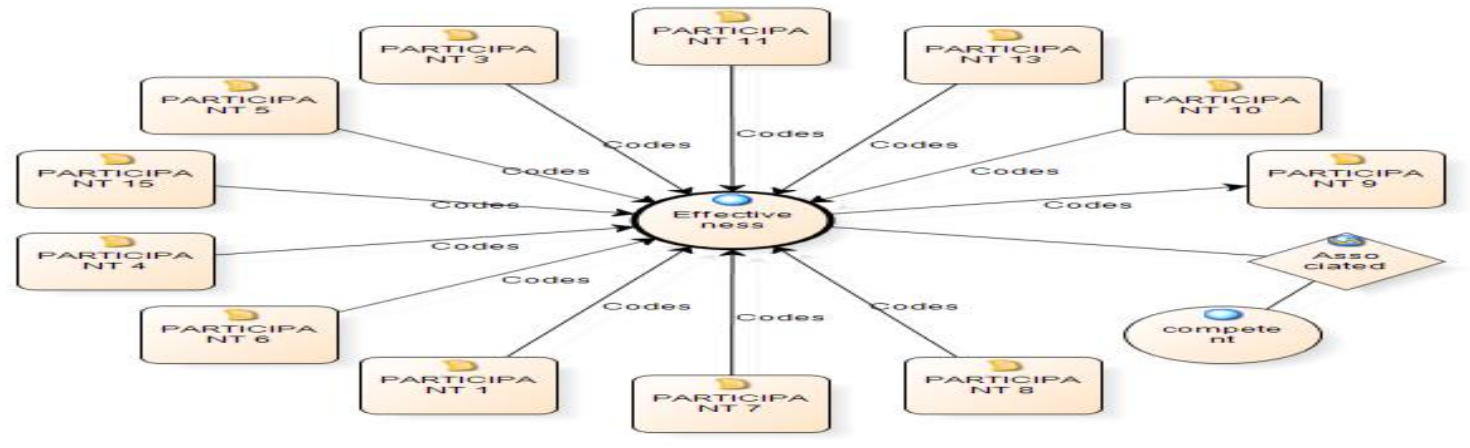

Fig 10: participant's source coded under Effectiveness

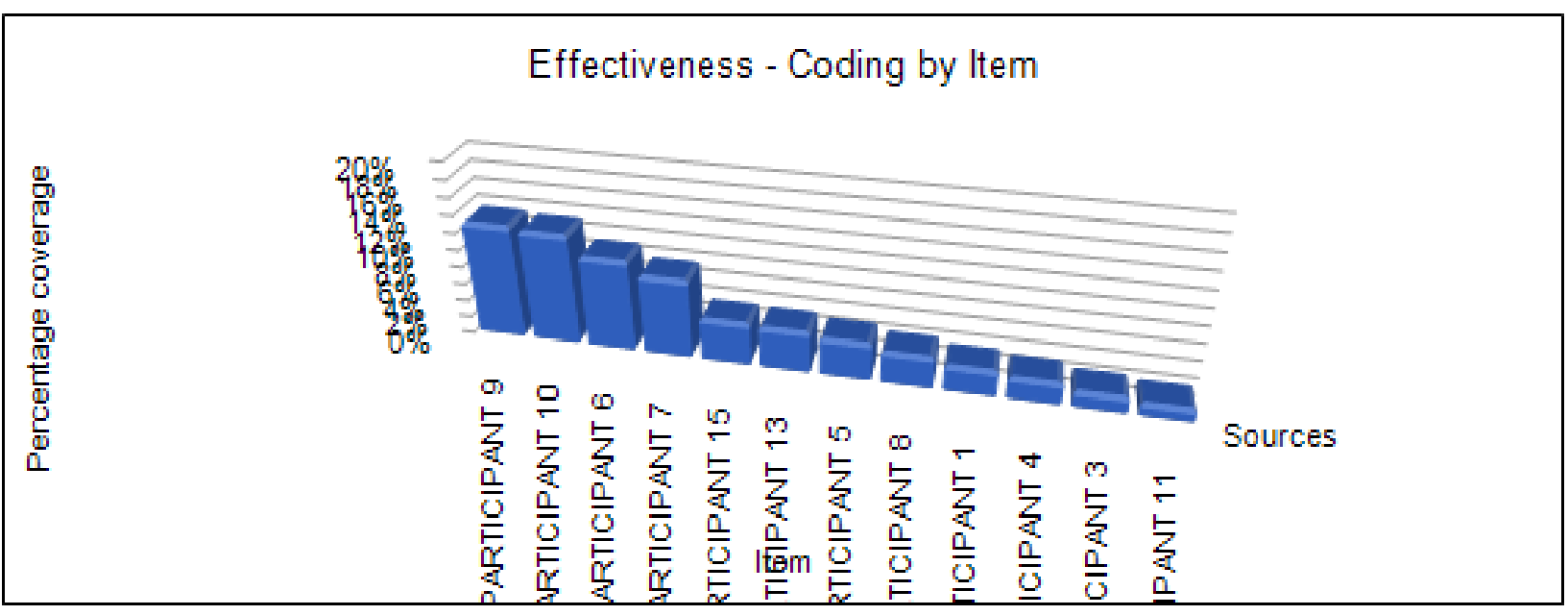

Fig 11: Participants source chart coded under Effectiveness 


\subsubsection{Efficiency}

The efficiency of the new way of learning has been more meaningful to this study. As members gives perspective of how efficient the framework is. Members dependably have the intrinsically self - illustrative visual and course materials constantly accessible online.
From the coded diagram in Fig 12 and Fig 13 many participants have greater sense of relieve from the use on the traditional way of delivering notes. The only problem they mentioned to make the system inefficient was the frequent power shortage.

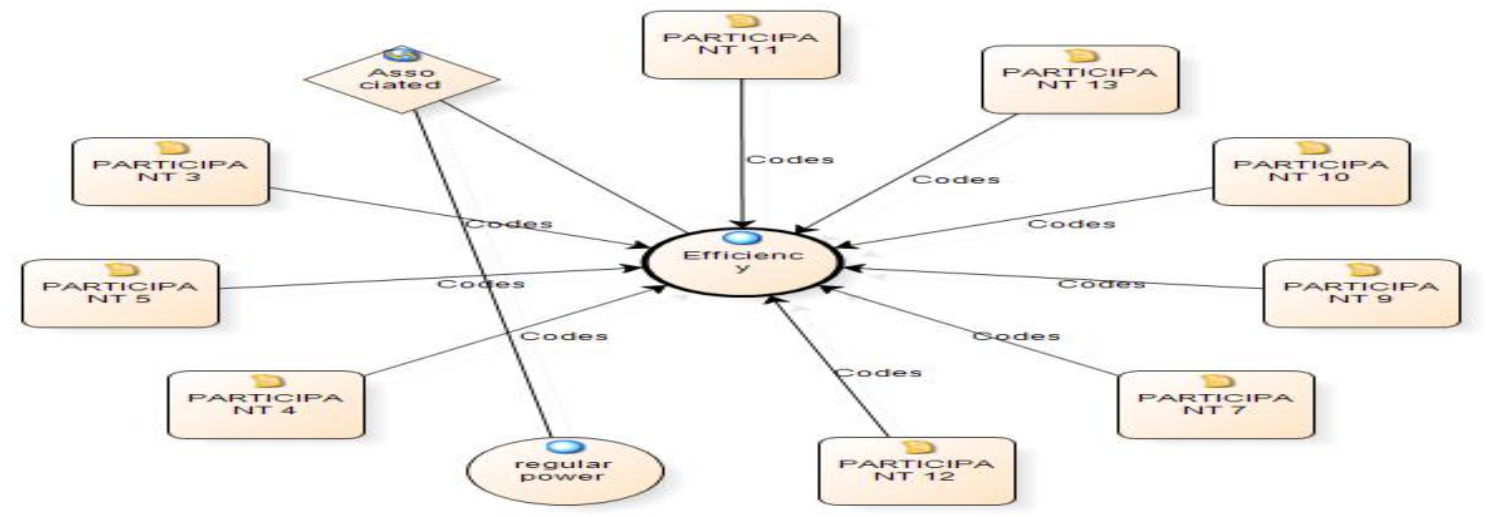

Fig 12: participants' sources coded under Efficiency

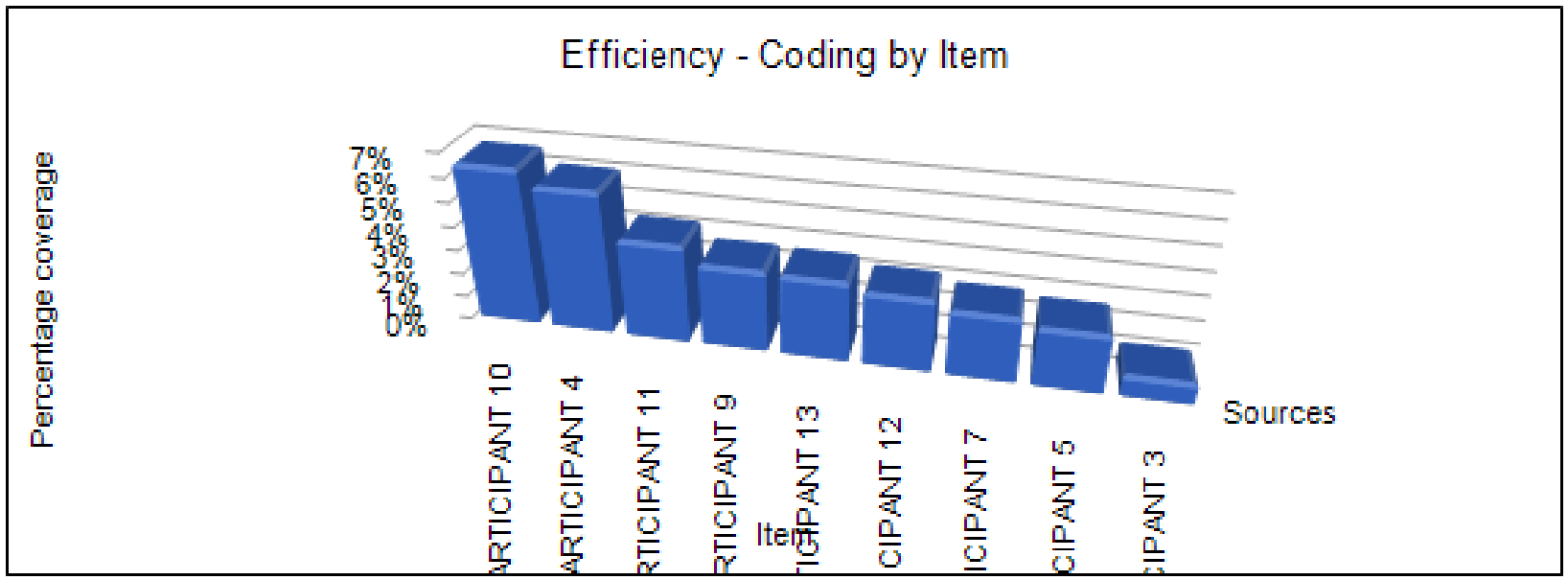

Fig 13: Participants' source chart under efficiency

\subsection{Overall View or Judgment}

The overall view of participants was sought on whether the technology is believed to be successful in its aim to support and improves the traditional way of teaching and learning. Participants' responses were analyzed and summarized under the node and chart as shown below. Majority of the participants were seen encouraging and there is the need for government support for the new system.

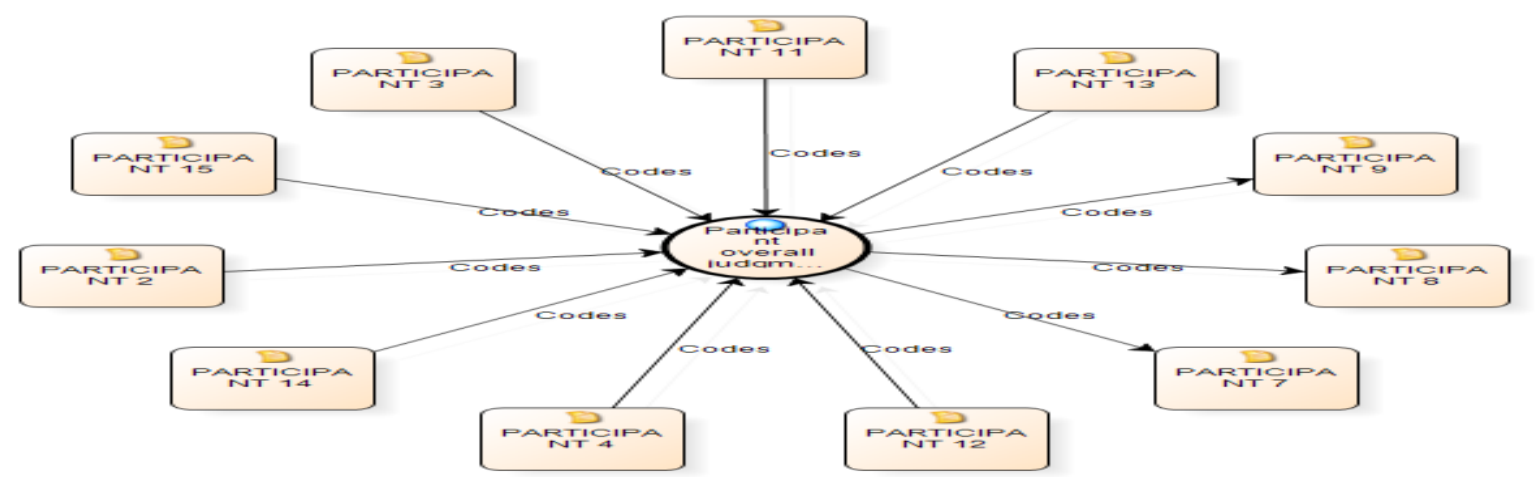

Fig 14: Participants source coded under technical overall view 


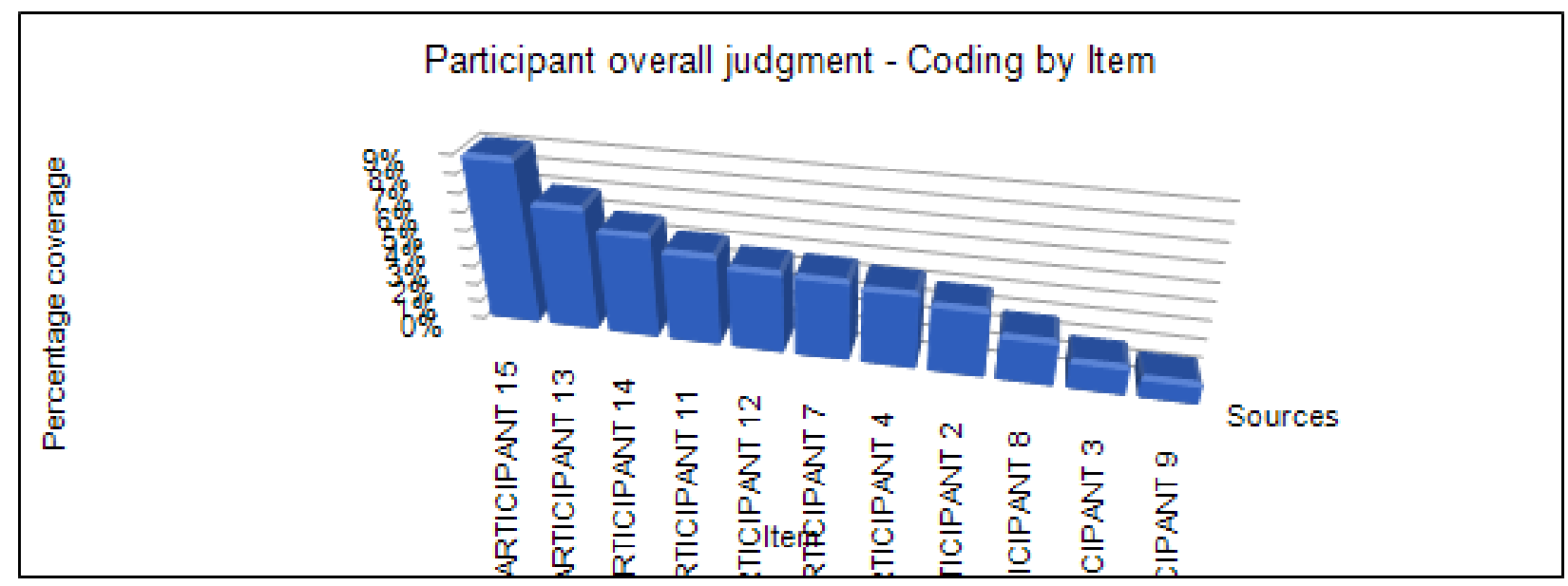

Fig 15: Participants source chart coded under technical problem

\section{CONCLUSSION}

This work provided a number of insights in respect of using elearning environment to support teaching and learning. It however, leaves a range of issues that could benefit from further academic and research study. Theoretical recommendations based on this participatory action case research merit further study in the current school curriculum and in the development of new curriculum for the basic School level of education and also in the design and implementation of lifelong e-learning and information and communication technology (ICT) programme for basic Ghanaian schools. It is in this light that this study would make the following recommendations:

An extended full-scale action research be conducted that will include more subjects that are offered at the basic level schools and the project be adequately resourced to lead to learners taking the Basic Certificate Examination Level in the respective subjects using the technology-mediated delivery. This will enable the method to be fully evaluated for practicability and efficiency. Potential continuation in this direction could utilize a positivist case study based approach to highlight the potential depth of issues on the use of elearning. It is my belief and conviction from this research that the above recommendations will go a long ways to finding last solutions to the many problems facing our basic schools that militate against their ability to play meaningful role in unravelling information and knowledge-based in our educational system.

\section{REFERENCES}

[1] Ussiph N, 2012. Using a Virtual Learning Environment to Support Teaching and Learning, and to Bridge the Digital Divide between Urban and Rural Communities in Ghana, PhD thesis University of Salford, Manchester.

[2] Gunasekaran, Ronald D, McNeil, Dennis Shaul,2002. E-learning: research and applications, Industrial and Commercial Training, Vol 34 Issue 2, page 44-53

[3] Alexander S. 2001. E-Learning Developments and Experiences, Education \& Training, Vol 43, No. 4-5, pages $240-248$.

[4] Kanuka, H. 2006. Instructional Design and E-learning: A Discussion of Pedogogical Content Knowledge as a Missing Construct, E-Journal of Instructional Science and Technology, Vol 9 , No 6
[5] Horton W. 2001. Leading E-Learning , American Socienty for Traininbg and Development, Websit URL: http://www.elearninggurus.com/articles.html.

[6] Hadjerrouit, S. 2007. Applying a System Development Approach to Translate Educational Requirements Into eLearning, Interdisciplinary Journal of Knowledge and Learning Objects, Vol 3,2007

[7] Siemens, G. \&Yurkiw, S. (2003). The Role of the Learner in e-Learning In G. M. Piskurich (Ed.), Preparing Learners for e-Learning. San Francisco, CA: Jossey-Bass / Pfeiffer

[8] Holmes, B. \& Gardner, J. (2008).e-Learning Concept and Practice. London: Sage

[9] Govindaswamy, T. (2002). "Successful Implementation of e-Learning Pedagogical Considerations", Internet and Higher Education Journal, Vol. 4, pp. 287-299.

[10] Harold, B. Jeff, L.1995. Don't Let Technology Pass You By, ABA Banking Journal, Box 986, Omaha, NE, page 73.

[11] Chao Boon Teo, Robert Kheng Leng Gay (2005b). "Personalization Issues in E-Learning," WSEAS Transactions on Information Science and Applications, Issue 10, Volume 2, , ISSN 1790-0832, pp. 1514 - 1522, October 2005.

[12] Heinich, R., Molenda, M., Russel, J. D. and Smaldino, S. E. (2002), "Instructional Media and Technologies for learning", 7th edition, Merrill Prentice Hall, ISBN 0-13030536-7.

[13] Diaz, D. P. and Bontenbal, K. F. (2000), "PedagogyBased Technology Training",In P. Hoffman, and D. Lemke (Eds.), Teaching and Learning in a Network World, Amsterdam, Netherlands: IOS Press, pp. 50-44.

[14] Kirschner, P. A. (2006), "Learning is Interaction", Utrecht: 2006, 26 Pages Including References and Notes ISBN 90-9020572-1.

[15] Olgren, C. H. (1998), "Improving Learning Outcomes: The Effects of Learning Strategies and Motivation", In C. Gibson (Ed.) Distance Learners in Higher Education: Institutional Responses for Quality Outcomes pp. 77-95, Madison, WI: Atwood. 
[16] Klein, H., \& Myers, M. D. (1999).A Set of Principles For Conducting and Evaluating Interpretive Field Studies In Information Systems. MIS Quarterly, Vol. 23(No. 1), 67-94.

[17] Mayer, R. (2004), "Should There be a Three-Strike Rule against Pure Discovery of Learning? The Case for Guided Methods of Instruction", American Psychologist 59 (1), pp. 14-19.

[18] McNiff, J. \& White, J. (2010) You and your action research project, $3^{\text {rd }}$ ed. Oxon: Rougledge.

[19] Myers, M. D. (1997). Qualitative Research in Information Systems.MIS Quarterly 21(2)

[20] Cisco Systems, Inc (2000) "Reusable Learning Object Strategy - Definition, Creation process andGuidelines for Building". Version 3.1, April 22, 2000.

[21] Lincoln, Y. S., \&Guba, E. G. (1985).Naturalistic Inquiry. Beverly Hills, CA: Sage.

[22] Koohang, A. (2004) "Creating Learning Objects in Collaborative e-Learning settings", Issues inInformation Systems Vol. 4 (2), pp 584-590

[23] Tam, M. (2000). Constructivism, instructional design, and technology: Implications for transforming distance learning. Educational Technology \& Society, 3(2), 5060.

$$
\text { Retrieved }
$$

from http://www.ifets.info/journals/3_2/tam.html.

[24] Valiathan, P. (2002), "Blended Learning Models. Learning Circuits", ASTD, Website URL: http://learningcircuits.org/2002/aug2002/valiathan.html

[25] Klein, HK. Myers, MD. (1999), 'A classification scheme for interpretive research in information systems', Qualitative research in IS: issues and trends, Idea Group Publishing, Herschey PA, pp. 218-239.
[26] Savenye, WC. Robinson, RS.(1996), "Qualitative issues and methods: An introduction for educational technologists, IAP, Carolina.

[27] Schwandt, T.A. (2000). "Three epistemological stances for qualitative inquiry: Interpretivism, hermeneutics and social constructionism. In N.K. Denzin \& Y.S. Lincoln (Eds), Handbook of qualitative research $\left(2^{\text {nd }}\right.$ ed, pp189213), Thousand Oaks, CA: Sage.

[28] Holliday, A.(2007), "Doing and Writing Qualitative Research, Second Edition, SAGE Publications, London, Thousand Oaks, New Delhi.

[29] Chua, W. F. (1986),"Radical Developments in Accounting Thought". The Accounting Review. 61(4): pp.601-632.

[30] Orlikowski, W.J. Baroudi, J.J. (1991), "Studying information technology in organizations: research approaches and assumptions. Information Systems Research 2(1), 1-28.

[31] Creswell, J.W.(1998), "Qualitative Inquiry and Research Design, Choosing Among Five Approaches" SAGE Publication, Thousand Oaks, London, New Delhi.

[32] Miles, M. B., \& Huberman, A. M. (1994). Qualitative Data Analysis: An Expanded Sourcebook. Thousand Oaks, CA: Sage Publications.

[33] Morgan, G. \& Smircich, L.(1980) “ The Case of Qualitative Research". Pennsylvania State University.

[34] Strauss, A \& Corbin, J. (1998). Basics of Qualitative Research: Techniques and Procedures for Developing Grounded Theory. Thousand Oaks, CA: Sage Publications, Inc. 